\title{
Increased Cognitive Functioning in Symptomatic Huntington's Disease As Revealed by Behavioral and Event- Related Potential Indices of Auditory Sensory Memory and Attention
}

\author{
Christian Beste, ${ }^{1,2}$ Carsten Saft, ${ }^{3}$ Onur Güntürkün, ${ }^{4}$ and Michael Falkenstein ${ }^{1}$ \\ ${ }^{1}$ Institut für Arbeitsphysiologie an der Universität Dortmund-Leibniz Research Centre for Working Environment and Human Factors, D-44139 Dortmund, \\ Germany, ${ }^{2}$ Department of Clinical Radiology, University of Münster, D-48149 Münster, Germany, ${ }^{3}$ Department of Neurology, Huntington Centre NRW, St. \\ Josef-Hospital, Ruhr-University Bochum, D-44791 Bochum, Germany, and ${ }^{4}$ Biopsychology, Institute for Cognitive Neuroscience, Faculty of Psychology, \\ Ruhr-University Bochum, 44780 Bochum, Germany
}

\begin{abstract}
Cognitive functions are thought to deteriorate globally in late stages of various neurodegenerative disorders. Here we describe that this general assumption is not justified and fails in Huntington's disease (HD). Presymptomatic gene mutation carriers (pHDs) and healthy controls performed worse compared with symptomatic HDs in an auditory signal detection task. During task performance, behavioral data and event-related potentials (ERPs) [i.e., MMN (mismatch negativity), P3a, and RON (reorienting negativity)] were recorded. Not only behavioral performance but also neurophysiological correlates of auditory sensory memory and attentional reorientation indicate enhanced performance occurring primal in late stages of a neurodegenerative disorder. Increased activity of the NMDA-receptor system, an assumed pathogenic mechanism in HD, might facilitate signal propagation at striatal level that enables more efficient task execution through a winner-take-all process. The results challenge the view that late stage neurodegeneration is necessarily related to a global decline in cognitive abilities in HD. In contrast, selectively enhanced cognitive functioning can emerge together with otherwise impaired cognitive functioning.
\end{abstract}

Key words: mismatch negativity (MMN); P3a; reorienting negativity (RON); sensory memory; attention; NMDA receptors; neurodegeneration; Huntington's disease (HD)

\section{Introduction}

Huntington's disease (HD) is an autosomal dominant neuropsychiatric disorder caused by CAG repeat expansion on chromosome 4 , which is accompanied by severe motor disturbances. The pathologic process in HD is characterized by severe neuronal loss in the striatum, although neocortical areas are also affected to a lesser degree. Several pathogenic mechanisms are discussed for HD (Beal and Ferrante, 2004), among them excitotoxicity (Beal and Ferrante, 2004). Excitotoxicity describes cell death that results from the activation of excitatory amino acid receptors. In HD, voltage-dependent NMDA receptors are assumed to be more receptive to endogenous levels of glutamate (Beal and Ferrante, 2004); thus glutamatergic neurotransmission is increased, leading to excitotoxic cell death.

NMDA-receptor mediated neural activity is important for

\footnotetext{
Received June 11, 2008; revised Sept. 21, 2008; accepted Sept. 25, 2008.

This work was supported by a grant from FoRUM, AZ-F479-2005, Ruhr-University Bochum. We thank all participants for their participation. We thank L. Blanke for committed technical assistance.

Correspondence should be addressed to Christian Beste, Institut für Arbeitsphysiologie an der Universität Dortmund-Leibniz Research Centre for Working Environment and Human Factors, Ardeystrasse 67, D-44139 Dortmund, Germany. E-mail: beste@ifado.de.

DOI:10.1523/JNEUROSCI.2659-08.2008

Copyright $\odot 2008$ Society for Neuroscience $\quad$ 0270-6474/08/2811695-08\$15.00/0
}

various cognitive functions, e.g., sensory memory. The so-called mismatch negativity (MMN) (Näätänen et al., 1978, 2007; Kujala et al., 2007) is assumed to be a reliable marker for auditory sensory memory. It is defined as a phasic negativity of the eventrelated potential (ERP) of the EEG evoked by rare deviant stimuli in a sequence of stimuli and may reflect the recognition of rare events deviating from frequent background events by the auditory system.

Studies examining neurochemical mechanisms underlying the MMN, systematically found that the MMN is modulated by NMDA receptors (for review, see Kujala et al., 2007; Näätänen et al., 2007). Consequently, the MMN is abolished after administration of NMDA-antagonists (Javitt et al., 1996; KreitschmannAndermahr et al., 2001; Umbricht et al., 2002). The dopaminergic, cholinergic, GABAergic or serotonergic receptor system, which are also affected in HD (Yohrling and Cha, 2002), have less consistently been reported to modulate the MMN (Kujala et al., 2007). Given a possible selective sensitivity of the MMN to the NMDA system, and based on an increased receptiveness to endogenous levels of glutamate in HD, one may expect that the MMN and hence sensory memory is enhanced in HD. This would sharply contrast with other cognitive functions, which are declined in HD (Craufurd and Snowden, 2002) and would more 
Table 1. Demographic, clinical, and neuropsychological data

\begin{tabular}{|c|c|c|c|c|c|c|}
\hline Test/parameter & HD & pHD & Control & HD versus $\mathrm{pHD}$ & HD versus control & $\mathrm{pHD}$ versus control \\
\hline IQ (MWT-B) & $109(5.3)$ & 110 (11.1) & $113(8.7)$ & ns & ns & ns \\
\hline \multicolumn{7}{|l|}{ Stroop test (UHDRS) } \\
\hline Color naming & $49.6(18.1)$ & $79.6(3.9)$ & $81.1(3.6)$ & $* * *$ & $* * *$ & ns \\
\hline Color reading & $69.6(15.8)$ & $94.2(8.0)$ & $93.7(5.1)$ & $* * *$ & $* * *$ & ns \\
\hline Interference & $29.2(13.0)$ & $49.9(4.6)$ & $52.1(3.5)$ & $* * *$ & $* * *$ & ns \\
\hline Symbol-Digit test (WAIS) & $38.8(13.9)$ & $53.7(5.5)$ & $55.3(3.4)$ & $* * *$ & $* * *$ & ns \\
\hline Word fluency (Benton) & $24.3(10.3)$ & 43.1 (13.6) & $46.2(9.6)$ & $* * *$ & $* * *$ & ns \\
\hline \multicolumn{7}{|l|}{ Digit span (WMS-R) } \\
\hline Forward & $4.6(0.8)$ & $9.3(1.2)$ & $9.1(1.1)$ & $* * *$ & $* * *$ & ns \\
\hline Backward & $2.6(1.0)$ & $8.1(1.6)$ & $8.0(0.9)$ & $* * *$ & $* * *$ & ns \\
\hline \multicolumn{7}{|l|}{ Block span (WMS-R) } \\
\hline Forward & $3.6(0.8)$ & $8.1(1.5)$ & $8.7(0.9)$ & $* * *$ & $* * *$ & ns \\
\hline Backward & $3.3(0.6)$ & $7.5(1.6)$ & $7.9(0.9)$ & $* * *$ & $* * *$ & ns \\
\hline Benton test (visual memory) & $8.1(2.3)$ & $13.6(0.8)$ & $13.5(0.9)$ & $* * *$ & $* * *$ & ns \\
\hline \multicolumn{7}{|l|}{$\begin{array}{l}\text { American Verbal Learning Test (AVLT) } \\
\quad[\text { German equivalent was used (VLMT)] }\end{array}$} \\
\hline Immediate word span & $3.7(0.8)$ & $7.3(1.1)$ & $7.6(1.4)$ & $* * *$ & $* * *$ & ns \\
\hline Final acquisition level & $7.2(1.7)$ & $13.6(1.3)$ & $13.7(0.8)$ & $* * *$ & $* * *$ & ns \\
\hline Interference test & $3.3(0.8)$ & $8.0(1.9)$ & $8.1(0.9)$ & $* * *$ & $* * *$ & ns \\
\hline Postinterference recall I & $6.2(1.5)$ & $12.6(1.7)$ & $12.1(1.3)$ & $* * *$ & $* * *$ & ns \\
\hline Postinterference recall II & $5.9(2.1)$ & $12.7(1.6)$ & $11.7(1.1)$ & $* * *$ & $* * *$ & ns \\
\hline Mini Mental Status Examination (MMSE) & $27.1(2.1)$ & $29.4(0.5)$ & 30 & $* * *$ & $* * *$ & ns \\
\hline Beck Depression Inventory (BDI) & $3.6(0.7)$ & $5.6(0.6)$ & $5.1(0.6)$ & ns & ns & ns \\
\hline Young Mania Rating Scale (YMRS) & $3.5(0.4)$ & $3.1(0.4)$ & $3.6(0.4)$ & ns & ns & ns \\
\hline
\end{tabular}

The table describes and compares performance in standard neuropsychological testing. Also a test revealing the affected status of all groups is given. For all tests and subtests, the performance of each group is given (mean \pm SEM). Bonferroni-corrected significances are given one-tailed ${ }^{* * *} p<0.001 ; * * 0.01$; ns, not significant). In all tests of standard neuropsychological assessment, the symptomatic HD group revealed significantly weaker performance than the presymptomatic and control groups. The latter groups did not differ from each other. The groups did not differ with respect to their premorbid IQ and the affective status (as revealed by BDI and YMRS). MWTB, Mehrfachlwahl Wortschatztest; WAIS, Wechsler Intelligence Scale; WMS-R, Wechsler Memory Scale (Revised).

${ }^{a}$ German equivalent was used [Verbaler Lern- und Merkfähigkeitstest (VLMT)].

generally challenge the view that late-stage, severe neurodegeneration is necessarily related to a global decline in cognitive abilities.

The MMN is usually followed by the $\mathrm{P} 3 \mathrm{a}$, which likely reflects a shift/switch of attention (Escera and Corral, 2007). Some other recent studies further describe an additional negativity after the P3a (Schröger and Wolff, 1998; Berti and Schröger, 2001), which is proposed to reflect neural processing in the context of reorienting of attention toward task-relevant aspects of stimulation after attention has been directed to a perturbating distractor (Schröger et al., 2000): the reorienting negativity (RON). For these functions a dependence on the NMDA-receptor system has not been described, yet.

\section{Materials and Methods}

Participants. In total, 26 right-handed HD gene mutation carriers $(n=$ 26) participated in the study. Thirteen of them were right-handed, unmedicated patients $(n=13)$ from 26 to 57 years of age $[$ mean $(M)=37.6$; $\mathrm{SD}=9.5$ ] (CAG: $\mathrm{M}=47.3 ; \mathrm{SD}=5.2)$ with manifest symptoms [Unified HD Rating Scale (UHDRS) motor score: $\mathrm{M}=25.3$; $\mathrm{SD}=10.6$ ].

In addition to those, a group of 13 right-handed presymptomatic gene mutation carriers $(n=13)$, defined by a positive gene test (CAG: mean $=$ $42.5 ; \mathrm{SD}=1.6)$ and absence of specific motor symptoms (pHD) $(\mathrm{UH}-$ DRS motor score $=0)$ from 24 to 56 years of age $(M=37.07 ; \mathrm{SD}=9.1)$ were recruited. The mean estimated age of onset [calculated by the formula of Ranen et al. (1995)] was 46.73 ( $S D=3.9$ ). All symptomatic patients and pHDs accepted to be videotaped to document their neurological status. Neurological assessment of the pHD group revealed no symptoms specific for HD.

Additionally, a group of 12 right-handed, healthy controls was recruited $(n=12)$. The mean age was $37.9(\mathrm{SD}=10.1)$. All recruited groups had a comparable educational background. Test scores of neuropsychological and affective testing of all groups are given and compared in Table 1.

All participants gave written informed consent. The study was approved by the ethics committee of the University of Bochum.
Stimuli and procedure. Subjects performed a distraction paradigm (see also Schröger and Wolff, 1998) in which tones at three different frequencies $(1000 \mathrm{~Hz}, 1100 \mathrm{~Hz}, 900 \mathrm{~Hz})$ were presented at two different lengths $(400 \mathrm{~ms}, 200 \mathrm{~ms})$. The standard tone $(1000 \mathrm{~Hz})$ occurred with a probability of $80 \%$, the deviant tones $(1100 \mathrm{~Hz}, 900 \mathrm{~Hz})$ occurred with $10 \%$ probability each. Each of the tones could be equally probably of long or short duration (400 ms, $200 \mathrm{~ms}$ ). The subjects had to react with one of the thumbs to indicate whether the tone was long (left response key) or short (right response key), regardless of tone frequency which was task irrelevant. Thus, the deviant tones served as distraction from this task-relevant responding.

Data processing. EEG was recorded from $28 \mathrm{Ag}-\mathrm{AgCl}$ electrodes (Fpz, Fp1, Fp2, Fz, F3, F4, F7, F8, FCz, FC3, FC4, FC5, FC6, Cz, C3, C4, C7, C8, $\mathrm{Pz}, \mathrm{P} 3, \mathrm{P} 4, \mathrm{P} 7, \mathrm{P} 8, \mathrm{Oz}, \mathrm{O} 1, \mathrm{O}_{2}$, left mastoid, M1; right mastoid, M2) against a reference electrode located on $\mathrm{Cz}$. Additionally, eye movements were monitored and recorded by means of two lateral and four vertical EOG electrodes. Electrode impedances were kept $<5 \mathrm{k} \Omega$. The EEG was filtered with a bandpass from $0.05-80 \mathrm{~Hz}$ and sampled with a rate of 500 $\mathrm{Hz}$. The EEG was re-referenced off-line to linked mastoids. Artifact rejection procedures were applied twice: automatically, with an amplitude threshold of $\pm 80 \mu \mathrm{V}$, and visually by rejecting all trials contaminated by technical artifacts. Horizontal and vertical eye movements preserved in the accepted trials were corrected by means of a linear regression method for EOG correction (Gratton et al., 1983). The MMN was measured in the difference waveshapes of deviant minus standard ERPs (Kujala et al., 2007). In the difference wave the MMN was defined as the most negative peak at 100-250 ms. The P3a as the most positive peak between 300 and $500 \mathrm{~ms}$, and the RON as the most negative peak between 400 and $600 \mathrm{~ms}$, from change onset. The amplitudes and latencies of all three components were measured at the electrodes F3, Fz, F4, FC3, FCz, FC4, C3, Cz, C4. This electrode grid was analyzed using the factors "laterality" (left, central, right) and "row" (F-row, FC-Row, C-row).

Statistical analysis. All variables included into analysis were normal distributed as indicated by the Kolmogorov-Smirnov test $(Z<0.88 ; p>$ .420 ). Reaction times (RTs) and error rates were analyzed in separate repeated measures ANOVAs using "trial type" (standard or deviant) as within-subject factor and "group" (symptomatic HD, presymptomatic 

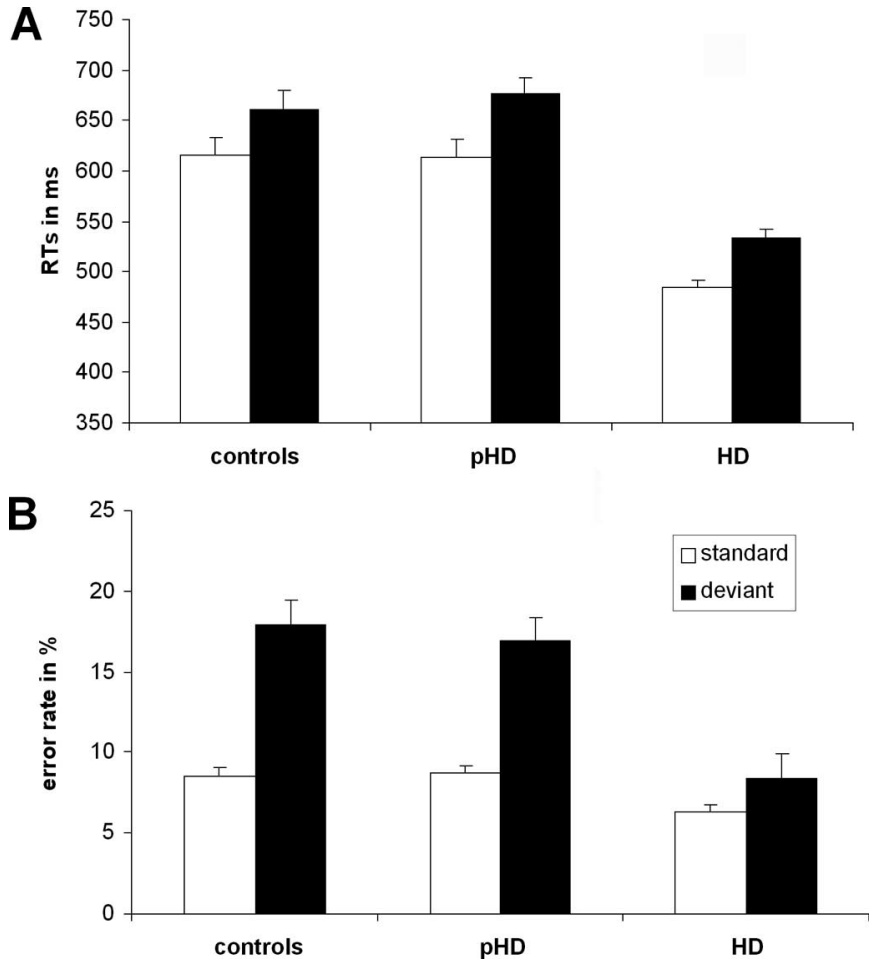

Figure 1. Behavioral data. $\boldsymbol{A}$, Mean reaction time (error bars indicate SEM) of the control, the presymptomatic (pHD), and the symptomatic (HD) group for the standard and deviant stimuli. $\boldsymbol{B}$, Mean error rates (error bars indicate SEM) of the control, the presymptomatic (pHD), and the symptomatic (HD) group for the standard and deviant stimuli.

$\mathrm{HD}$, controls) as between-subject factor. Amplitudes of the MMN, P3a and RON were analyzed in a repeated measures ANOVA using "laterality" (left, central, right) and "row" (frontal, fronto-central, central) as within-subject factors and "group" (symptomatic HD, presymptomatic $\mathrm{HD}$, controls) as between-subject factor. The degrees of freedom were adjusted using Greenhouse-Geisser correction when appropriate. Significances are given one-tailed. All post hoc tests including pairwise comparisons were calculated using the Bonferroni correction. For the descriptive data, means and SEM are given.

\section{Results}

\section{Behavioral data}

RTs and error rates for standard and deviant trials are reported (Fig. 1). RTs were longer in the deviant $(624.1 \pm 8.5)$, compared with the standard trials $(571.6 \pm 8.2)\left(F_{(1,35)}=51.29 ; p<0.001\right)$. This effect was not further modulated by the factor group, as indicated by the nonsignificant interaction "condition $\times$ group" $\left(F_{(2,35)}=0.51 ; p=0.601\right)$. Yet, the main effect group was significant $\left(F_{(2,35)}=35.01 ; p<0.001\right)$ : The symptomatic HD group showed faster RTs (mean $=508.9 ; \mathrm{SEM}=12.9)$ than the pHD $(645.7 \pm 12.9)$ and control group $(638.8 \pm 13.4)(p<0.001)$ (Fig. 1A). The latter groups did not differ from each other $(F<$ 1). Additionally, we examined effects of involuntary attentional switching by comparing RTs between standard trials after a deviant and standard trials after a standard trial. There was a switching effect $\left(F_{(1,35)}=8.91 ; p=0.005\right)$, indicating prolonged RTs after switching $(579.1 \pm 10.4)$, compared with nonswitching $(552.9 \pm 9.07)$. This effect was similar across all groups, as the nonsignificant interactions reveal $\left(F_{(2,35)}=0.03 ; p>0.9\right)$. However, there was a main effect group $\left(F_{(2,35)}=25.88 ; p<0.001\right)$, showing that HDs $(478.0 \pm 14.9)$ responded faster than controls $(607.7 \pm 15.5)$ and pHDs $(612.3 \pm 14.9)$. The latter groups did not differ from each other $(p>0.9)$.
For the error rates (Fig. $1 B$ ), the repeated-measures ANOVA revealed that errors were twice as frequent in the deviant $(14.43 \pm$ $0.85)$, compared with standard trials $(7.85 \pm 0.28)\left(F_{(1,35)}=\right.$ 56.11; $p<0.001)$. Overall the HD group committed less errors $(7.38 \pm 0.78)$ than the pHD $(12.82 \pm 0.77)(p<0.001)$ and the control group $(13.22 \pm 0.81)(p<0.001)\left(F_{(2,35)}=16.88 ; p<\right.$ $0.001)$. "Condition" and "group" interacted $\left(F_{(2,35)}=6.55 ; p=\right.$ $0.004)$. Post hoc tests revealed that the HD group showed less errors $(8.46 \pm 1.45)$ on deviant trials than the pHDs $(16.92 \pm$ $1.45)$ and the control group $(17.91 \pm 1.51)\left(F_{(2,35)}=18.70 ; p<\right.$ $0.001)$. On the standard trials the groups showed a similar pattern; i.e., the HD group showed less errors $(6.31 \pm 0.48)$ than the pHDs $(8.71 \pm 0.47)$ and the control group $(8.54 \pm=0.53)$ $\left(F_{(2,35)}=7.59 ; p<0.002\right)$. In summary, the behavioral data showed better performance for the symptomatic HD group compared with the $\mathrm{pHD}$ and control group.

\section{Electrophysiological data}

Difference waves (deviant minus standard) are shown in Figure 2. MMN, P3a and RON are well seen in all subjects. The maps of the components are shown in Figure 3.

\section{Mismatch negativity}

The MMN was analyzed in a repeated measures ANOVA, means and SEM are given. The repeated measures ANOVA of the amplitudes revealed a significant main effect of "row" $\left(F_{(2,70)}=\right.$ 33.07; $p<0.001)$. Bonferroni-corrected post hoc tests showed that the amplitudes were larger at frontal $(-6.42 \pm=0.33)$ and fronto-central $(-6.89 \pm 0.41)$ sites than at central $(-4.37 \pm$ $0.42)$ sites $(p<0.001)$. The main effect of "laterality" was not significant $\left(F_{(2,70)}=1.30 ; p=0.277\right)$, but there was a significant interaction "laterality $\times$ group" $\left(F_{(4,70)}=6.57 ; p<0.001\right)$. Subsequent univariate ANOVAS revealed that the groups did not differ at left-sided $\left(F_{(2,35)}=0.94 ; p=0.400\right)$ and central leads $\left(F_{(2,35)}=0.55 ; p=0.552\right)$, but on right-sided leads $\left(F_{(2,35)}=\right.$ $16.48 ; p<0.001)$. Here the symptomatic group showed higher amplitudes $(-9.50 \pm 0.68)$ than the pHDs $(-4.55 \pm 0.68)$ and the controls $(-4.77 \pm 0.72)$. In addition the factor "group" itself was significant $\left(F_{(2,35)}=5.00 ; p=0.012\right)$. Post hoc tests showed that the symptomatic group showed overall larger amplitudes $(-7.44 \pm 0.59)(p<0.030)$ than the control $(-5.10 \pm 0.61)$ and pHD group $(-5.14 \pm 0.59)$. All other possible interaction effects did not reach significance (all $F$ values $<0.95 ; p>0.2$ ).

The repeated-measures ANOVA of the latencies revealed a significant main effect of "row" $\left(F_{(2,70)}=17.09 ; p<0.001\right)$. Bonferroni-corrected post hoc tests showed shorter latencies at frontal (144.45 \pm 3.14$)$ and fronto-central sites $(146.50 \pm 3.25)$ than at central $(158.56 \pm 3.09)$ sites $(p<0.001)$. There was also a significant main effect of group $\left(F_{(2,35)}=16.87 ; p<0.001\right)$ : the symptomatic HD group revealed shorter latencies (127.40 \pm 4.75) than the pHDs $(157.42 \pm 4.75)$ and controls (164.69 \pm 4.95) ( $p<0.001)$. All other main or interaction effects were not significant (all $F$ values $<0.55 ; p>0.762$ ).

In summary, the MMN was larger and occurred earlier for the symptomatic HD group compared with the $\mathrm{pHD}$ and control group, the amplitude effect being restricted to the right side.

\section{P3a}

The P3a at the different electrode sites is also given in Figure 2. The repeated-measures ANOVA of the amplitudes revealed no main or interaction effect (all $F$ values $<1.67$; $p>0.110$ ). Also there was no main effect or interaction for the latencies (all $F$ values $<2.32 ; p>0.112$ ). 

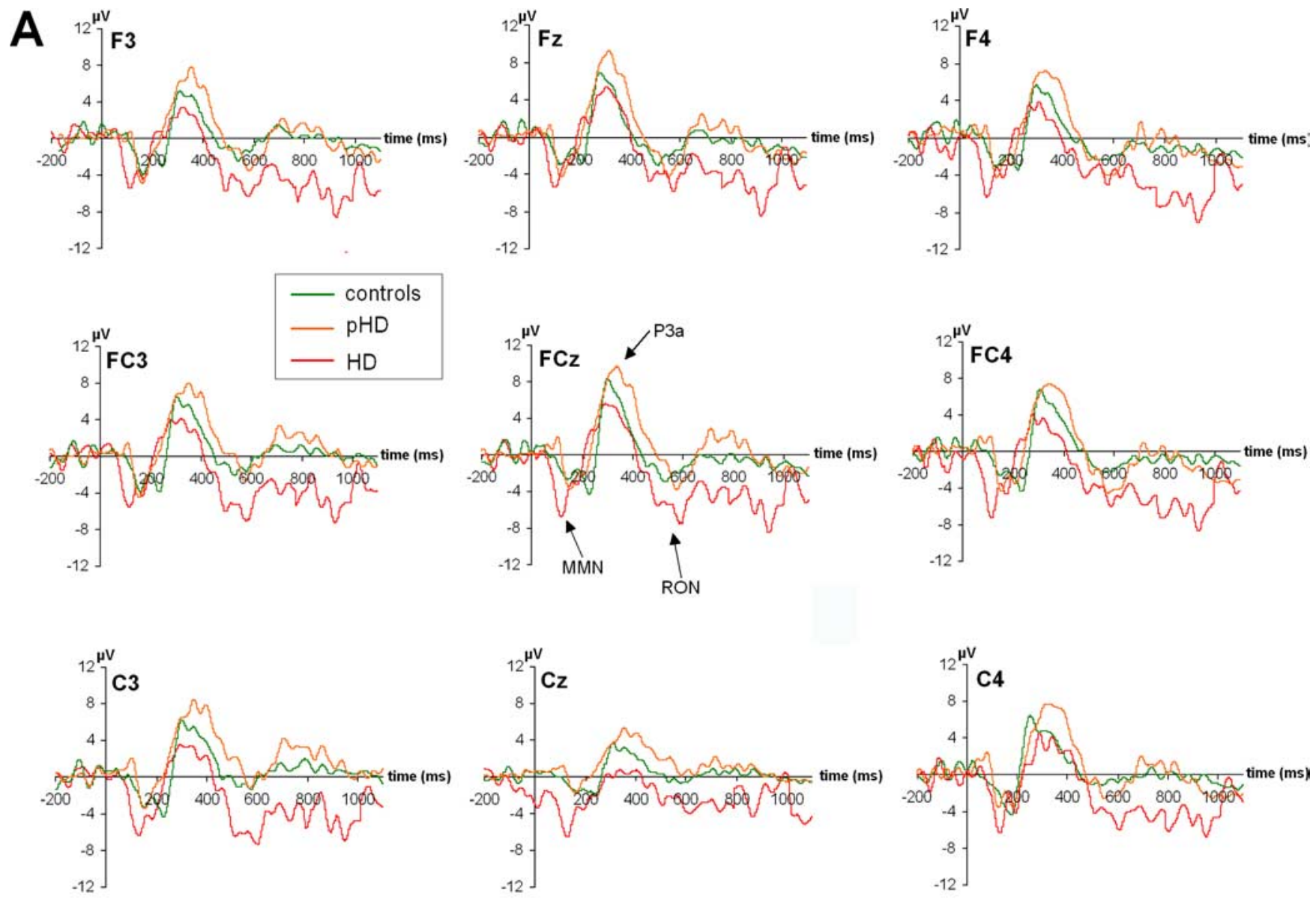

B
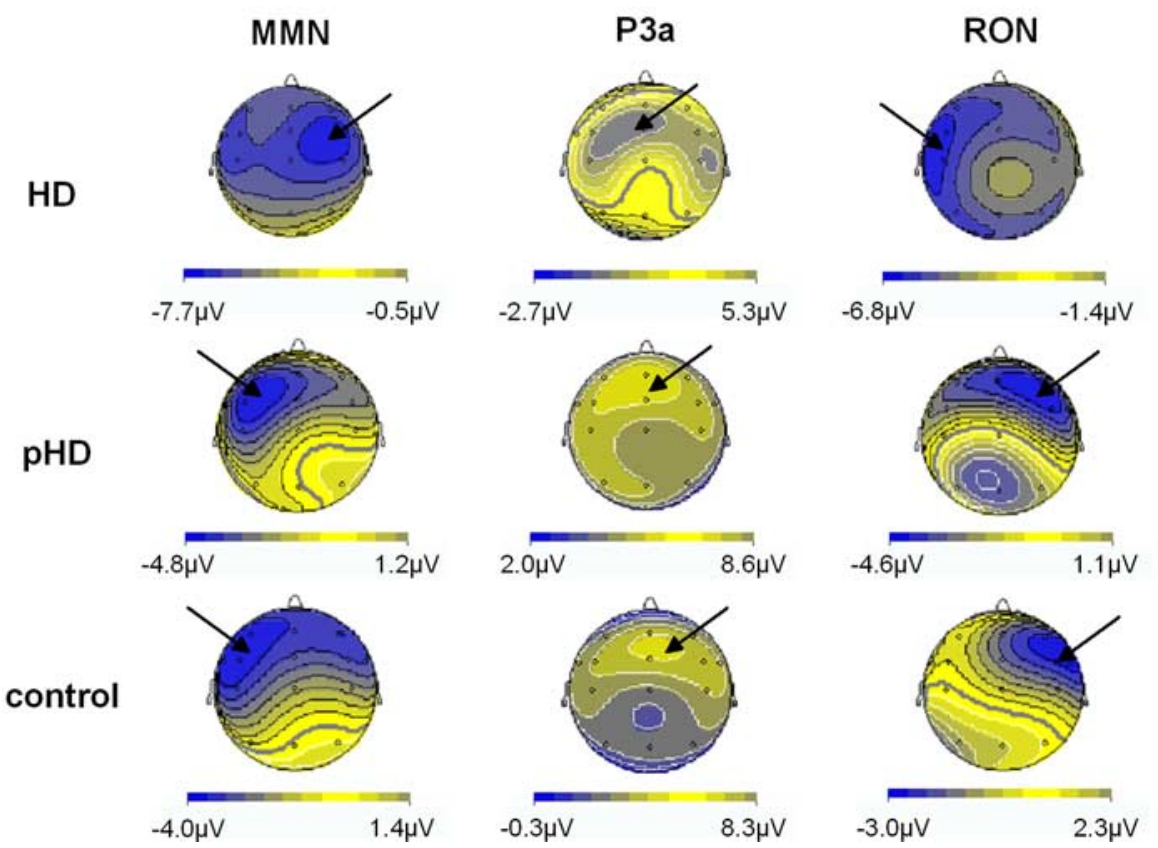

Figure 2. Neurophysiological data (difference waves). $\boldsymbol{A}$, Time course of the ERPs. For all electrodes shown, the time course from $200 \mathrm{~ms}$ before tone onset (twice) until $1100 \mathrm{~ms}$ beyond tone presentation is given. Red lines denote the ERP time course of the HD group, orange lines of the pHD group, and green lines of the control group. $\boldsymbol{B}$, The scalp topography pattern of the different ERP components (i.e., MMN, P3a, and RON). These are separated for the HD, pHD, and control groups. Note the different scaling of the scalp topography maps.

\section{Reorienting negativity}

The RON is defined as the negative deflection in the difference waves between 400 and $600 \mathrm{~ms}$ after tone onset (Fig. 2). Means and SEM are given. The repeated-measure ANOVA of the ampli- tudes revealed a significant main effect "row" $\left(F_{(2,70)}=8.09 ; p=\right.$ 0.001). Post hoc tests showed that the amplitudes were larger at frontal $(-4.60 \pm 0.25)$ and fronto-central $(-4.34 \pm 0.19)$, than at central sites $(-3.29 \pm 0.39)(p<0.001)$. The main effect 

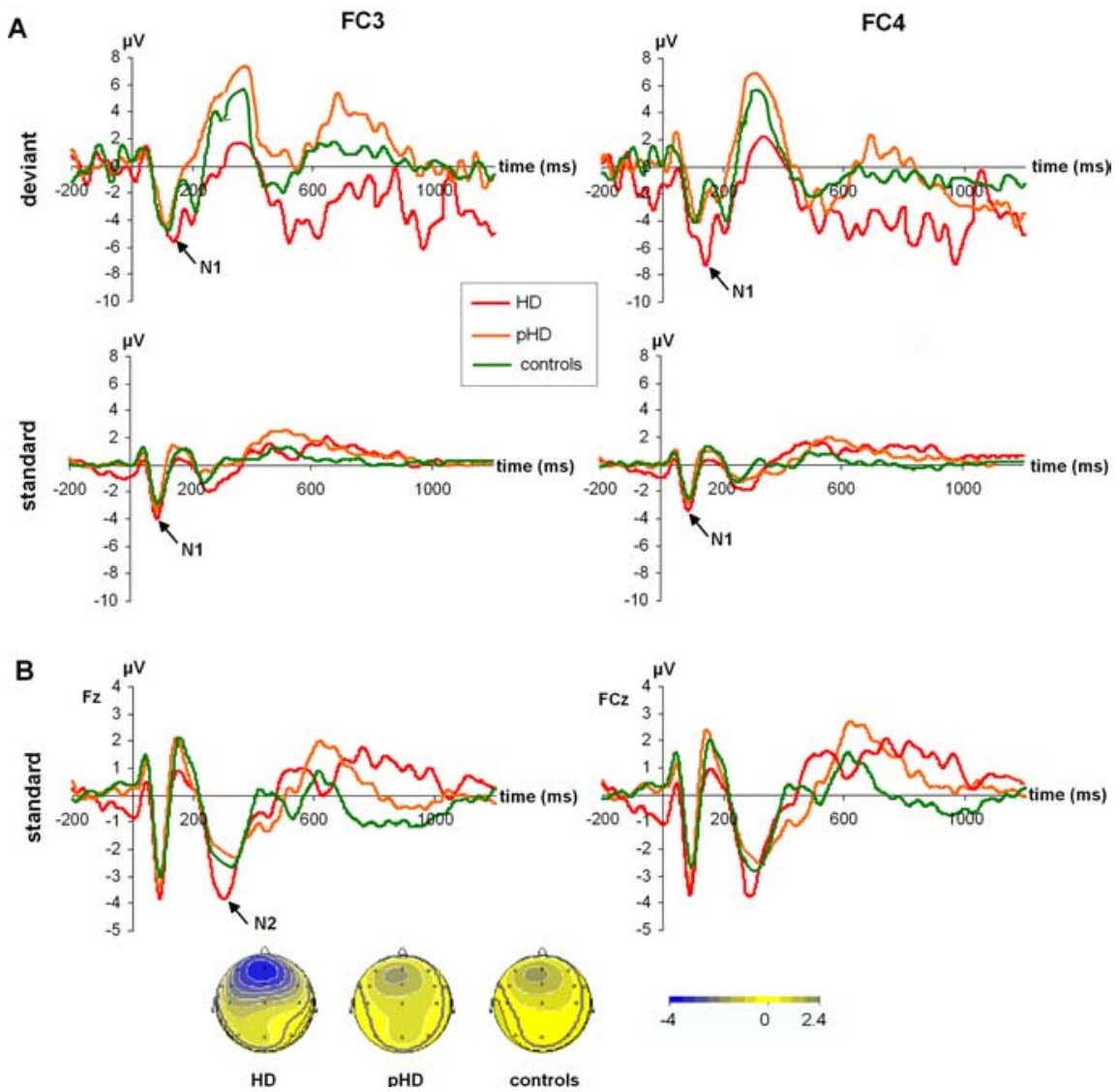

Figure 3. Neurophysiological data (original ERPs). $\boldsymbol{A}$, ERPs on deviant and standard trials at electrodes FC3 and FC4. As can be seen, the N1, which contributes to the modulations of the MMN, does not differ between groups on standard trials, but on deviant trials. Here this was especially the case for the HD-group at electrode FC4, where the MMN was also maximal. $\boldsymbol{B}$, ERPs on standard trials at electrodes Fz and FCZ. A N2 with clear topography is seen that was stronger in HDs, compared with the other groups. Note that the scaling in $\boldsymbol{A}$ is different from that in $\boldsymbol{B}$.

"laterality" was not significant $\left(F_{(2,70)}=1.39 ; p=0.256\right)$, but there was a significant interaction "laterality $\times$ group" $\left(F_{(4,70)}=\right.$ 5.02; $p=0.001)$. Subsequent univariate ANOVAS revealed that the groups did not differ at right-sided leads $\left(F_{(2,35)}=0.75 ; p=\right.$ $0.478)$, but on central $\left(F_{(2,35)}=12.94 ; p<0.001\right)$ and left-sided leads $\left(F_{(2,35)}=74.55 ; p<0.001\right)$. On central and left-sided leads, the symptomatic HD group showed higher amplitudes than the other groups $(p<0.001)$, which did not differ from each other $(p>0.9)$ [left-sided leads: controls $(-2.29 \pm 0.30), \mathrm{pHD}$ $(-2.21 \pm 0.29), \mathrm{HD}(-6.68 \pm 0.29)$; central leads: controls $(-3.70 \pm 0.40), \mathrm{pHD}(-3.19 \pm 0.39), \mathrm{HD}(-5.84 \pm 0.39)]$. In addition, the factor "group" itself was significant $\left(F_{(2,35)}=17.12\right.$; $p<0.001)$. Post hoc tests revealed that the symptomatic group showed larger amplitudes $(-5.83 \pm 0.36)$ than the control $(-3.01 \pm 0.36)$ and $\mathrm{pHD}$ group $(-3.04 \pm 0.36)(p<0.001)$. All other possible interaction effects did not reach the level of significance (all $F$ values $<1.37 ; p>0.252$ ).

The repeated-measures ANOVA of the latencies revealed no significant main or interaction effect (all $F$ values $<1.33$; $p>$ 0.270 ). In summary, the RON was larger for the symptomatic HD group than for the other groups at left-sided and midline leads.

\section{Original ERPs}

With respect to be $\mathrm{MMN}$ it may be important to examine whether the MMN is partly modulated by the N1 (Schröger et al., 2007). To account for this we analyzed the N1 at electrode FC3 and FC4 (Fig. 3A) as the MMN was largest at these electrodes, depending on groups. For the N1 we found a main effect of "trial type" $\left(F_{(1,35)}\right.$ $=27.62 ; p<0.001)$ showing that the N1 was larger on deviant $(-3.71 \pm 0.15)$ than on standard trials $(-4.81 \pm 0.11)$. Furthermore, there was a main effect "group" $\left(F_{(2,35)}=6.35 ; p=0.004\right)$. The HDs showed the largest N1 $(-4.70 \pm 0.15)$ differing from the pHD $(-4.11 \pm 0.13)$ and controls $(-3.97 \pm 0.10)(p<0.028)$. Additionally there was a interaction "electrode $\times$ group" $\left(F_{(2,35)}=59.48 ; p<\right.$ $0.001)$. Bonferroni-corrected post hoc test showed that the groups did not differ at electrode FC3 $\left(F_{(2,35)}=1.41 ; p=0.258\right)$, but at electrode FC4 $\left(F_{(2,35)}=16.15 ; p<\right.$ $0.001)$. Here it is shown that controls $(-3.92 \pm 0.17)$ and $\mathrm{pHDs}(-3.89 \pm 0.16)$ did not differ from each other $(p>0.9)$ but both differed from the HDs showing the largest N1 $(-5.07 \pm 0.16)$. This effect was further modulated by the factor "trial type" as revealed in the interaction "trial type $\times$ electrode $\times$ group" $\left(F_{(2,35)}=\right.$ 50.23; $p<0.001)$. This interaction is due to the fact that the largest difference between the electrode sites (FC3, FC4) was observed in the deviant condition, selectively for the HD group (standard: $-4.70 \pm 0.19$; deviant: $-6.41 \pm 0.22$ ) $(\eta=0.77)$. For the other groups and trial types, the difference between the electrodes sites were smaller (all $\eta$ values $<0.31$ ).

The behavioral data show that overall, HDs had faster RTs than the other groups. Recent studies indicate a strong relation of RTs and the N2latency (Beste et al., 2008; Gajewski et al., 2008). Hence the N2 on standard trials was analyzed. The N2 was maximal at electrodes $\mathrm{Fz}$ and $\mathrm{FCz}$ (Fig. 3B). Amplitudes differed between the groups $\left(F_{(2,35)}=22.59 ; p<0.001\right)$. Here the HD group revealed the strongest $\mathrm{N} 2(-4.50 \pm 0.21)(p<0.001)$, whereas the controls $(-2.79 \pm 0.21)$ and $\mathrm{pHDs}(-2.69 \pm 0.20)$ did not differ from each other $(p>0.9)$. The latencies were shortest in HDs (267.7 \pm 4.19), compared with pHDs (325.6 \pm 4.1$)$ and controls (331.8 \pm 4.36) $(p<0.001)\left(F_{(2,35)}=69.36 ; p<0.001\right)$. The latter groups did not differ from each other $(p>0.9)$. Additionally it is shown that N2-latencies were found to be related to RTs on standard trials and overall RTs in the HD group. For the other groups no such correlations were obtained [Fz: $r=0.718 ; p=0.003$ (RTs standard)]; $r=0.734 ; p=0.002$ (RTs overall) [FCz: $r=0.583$; $p=0.018$ (RTs standard) $; ; r=0.625 ; p=0.011$ (RTs overall). In the other groups, no relation was obtained (all $r$ values $<0.3 ; p>$ $0.4)$.

\section{Discussion}

In the current study, we investigated processes of sensory memory, attentional shifting and reallocation of attention in an auditory distraction paradigm in symptomatic and presymptomatic Huntington's patients and healthy controls. The symptomatic HD group showed higher MMN and RON amplitudes, shorter latencies and better behavioral performance (lower error rates, shorter RTs) compared with controls and pHDs. The P3a did not 
differ between the groups. Thus, a combination of behavioral and electrophysiological measures revealed that symptomatic HD patients display a clear advantage in a cognitive task.

The results show that specific cognitive functions, namely auditory sensory memory (reflected by the MMN) and reorientation of attention (reflected by the RON) are not deteriorated and can even be enhanced in late stage HD. Moreover, the results suggest that superiority in these functions emerge primal in the late stage of this disease, because pHDs performed worse. Thus, enhanced functioning can (1) not be attributed to a compensatory mechanism (Paulsen et al., 2004; Voermans et al., 2004; Feigin et al., 2006; Beste et al., 2007), which is restricted to the presymptomatic stage, and (2) not a perseverance of compensatory processes or of an unaffected function. The results are in sharp contrast to other neurodegenerative disorders, like Parkinson's and Alzheimer's disease, in which the MMN is reduced (Pekkonen, 2000). The results are also in sharp contrast to the usual dysfunctional cognitive abilities in HD (Craufurd and Snowden, 2002). Our study reveals that the assumption of a general cognitive decline during the course of neurodegeneration in HD has to be modified.

If the MMN reflects auditory sensory memory functions (Nätänen and Winkler, 1999; Schröger et al., 2004; Kujala et al., 2007) better performance in this function in HD dissociates from declined performance in working and long-term memory (Table 1, neuropsychological test data) (Craufurd and Snowden, 2002). Yet, these latter functions do not primarily rely on NMDAreceptor mediated neural transmission (Kalueff, 2007). It may therefore be assumed that the specific dependence of the MMN on the corticostriatal NMDA system underlies this dissociation of performance in $\mathrm{HD}$ as well as the enhancement and acceleration of the MMN. The NMDA-receptor system has been found to modulate the MMN (Javitt et al., 1996; KreitschmannAndermahr et al., 2001; Umbricht et al., 2002). Supporting this, conditions like Alzheimer's disease, stroke, schizophrenia as well as conditions of normal aging, known to decrease the MMN (Pekkonen, 2000; Ilvonen et al., 2003; Mager et al., 2005; Ahveninen et al., 2006), are accompanied by dysfunctions in the NMDA-receptor system. Especially the NR2A and NR2B receptor subunits are affected in these conditions (Villmann and Becker, 2007). In HD, genes coding for these receptor subtypes were found to modulate age of onset in HD (Arning et al., 2005), relating to an excitotoxic pathogenic mechanism (Beal and Ferrante, 2004). The observed change in lateralization in HDs, compared with pHDs and controls, may be due to degenerative processes inducing changes in plasticity that may be expressed by the crossed lateralization pattern.

However, as the analysis of the $\mathrm{N} 1$ shows, it was also larger in the deviant conditions, which was especially the case for the HD group. It is often found that attentional (N1) and sensory memory processes (MMN) may overlap (e.g., Schröger et al., 2007). As such the increase cannot solely be attributed to sensory memory, but also partly to attentional processes. However, the $\mathrm{N} 1$ also taps into memory functions (Schröger et al., 2007), but is in contrast to the MMN less sensitive to small changes in stimulation. Hence, both processes seem to be enhanced in HDs.

Recent research indicates that theP3a reflects (mainly involuntary) attention switching (Escera and Corral, 2007), which obviously did not differ between groups. Thus, the results show a dissociation of enhanced auditory sensory memory and unchanged attentional shifting/switching. The latter may be regarded to contrast with other results (Aron et al., 2003), but this study (Aron et al., 2003) focused on voluntary switching between different response sets. If the P3a reflects involuntary attentional switching/shifting widely decoupled from the response level, it seems that HDs do not have a problem with this type of involuntary switching, as induced by rare deviant events. This is substantiated by the finding that behavioral indicators of switching were not differentially modulated by the groups. The finding of generally faster RTs in the HD group is reflected in an earlier N2latency on standard trials, which was furthermore directly correlated with the RT on standard trials (Beste et al., 2008; Gajewski et al., 2008).

However, voluntary attentional or task switching may be impaired in HD. Further studies should directly compare the different types of attention switching with the same HD patients.

The observation that the reorientation of attention (reflected by the RON) was also increased in the HD group accords with the enhanced behavioral performance in the relevant task. Because MMN and RON are similarly modulated in HDs, they may depend on similar neural mechanisms. The finding of a crossed lateralization pattern of the MMN and RON in HDs opens the possibility that the neurodegeneration uncovers or induces a functional asymmetry of the underlying cognitive processes that are yet unknown.

Although the primary effects of neurodegenerative diseases like HD might be largely confined to certain cell populations in restricted areas of the brain, these changes can affect cognitive and motor systems at multiple levels of the brain. In most cases, the pathological alterations of neural systems result in a deterioration of cognitive functions. However, as shown in the present study, a pathogenic increase in responsiveness of a transmitter system can increase cognitive functions if these functions selectively depend on this neural system, whereas other cognitive functions (Table 1) are deteriorated. Thus, highly circumscribed elevations of cognitive functions can be embedded within a pattern of more general decline. However, Landwehrmeyer et al. (2007) could not ameliorate severeness of HD symptoms [assessed by the UHDRS (Huntington Study Group, 1996)] by drugs targeting NMDA-mediated neurotransmission. Yet, this study did not use tests revealing performances in sensory memory and attentional orientation on target stimuli. We assume that these functions are especially affected by the NMDA-dependent alterations of intrastriatal dynamics.

NMDA receptors are found in all basal ganglia nuclei, with the highest density being present in the striatum (Ravenscroft and Brotchie, 2000). The vast majority of striatal cells are the GABAergic medium spiny neurons (MSPs) that carry output to the globus pallidus and the substantia nigra. MSPs receive massive glutamatergic cortical input via AMPA and NMDAreceptors located on the heads of the spines with which their dendrites are covered (Bolam et al., 2000). Although MSPs create a dense inhibitory feedback network with their neighbors, these interactions can be characterized by low amplitude and high failure rate (Tunstall et al., 2002). Instead, a small number of GABAergic striatal fast-spiking interneurons seems to mediate the strong inhibition within the neostriatum in a feedforward manner (Tepper et al., 2004). These fast-spiking interneurons also receive glutamatergic cortical input. Together, these two GABAergic cell populations seem to create a complex "winnertake-all" network (Plenz, 2003). On cortical activation, fastspiking interneurons initially suppress previous striatal network states, after which the network, through GABAergic lateral connections, establishes a new focus of activity that correlates with the dominant cortical input (Plenz, 2003). For this new striatal focus to be established, fast spiking neurons and MSPs have to 
receive massive phasic cortical action potential bursts that switch an assembly of striatal neurons to an up-state (Calabresi et al., 2000). Corticostriatal NMDA receptors play a key role in this switch (Calabresi et al., 2000). MSPs are most affected in HD and their degeneration occurs progressively whereas fast spiking interneurons are more resistant (Cepeda et al., 2007). The concomitant change in the proportions of neuronal striatal populations could further sharpen the winner-take-all network, elevating the speed of establishment and the dominance of a winner-assembly that subsequently defines the striatal output. This last point is substantiated by the present observation that $\mathrm{pHD}$-subjects had no increase in task performance although their striatal NMDAreceptors were probably already more sensitized to glutamate than those of the healthy controls, but MSP neuron loss is not that expressed than in HD (Cepeda et al., 2007).

Our task required the subjects to establish the goal state of differentiating between short and long tones and to ignore the different frequencies. It is likely that this goal state, requiring top-down attentional processing to establish, was represented by neuronal assemblies mostly clustered in the prefrontal cortex (Miller, 2000; Miller and Cohen, 2001). The striatal output of these prefrontal units excites fast spiking neurons and MSPs via AMPA and NMDA receptors (Ravenscroft et al., 2000). If, in symptomatic HD-patients, striatal NMDA receptors are more receptive to endogenous levels of glutamate (Beal and Ferrante, 2004), the corticostriatal pathway should represent these goal states more reliably. As a consequence, intrastriatal winner-takeall mechanisms will constitute these goal states with high reliability. This then should result in faster reaction times and lower error rates. Concomitantly, ERPs that reflect the process of sensory memory and reorientation to the targets should be increased because they incorporate the goal state represented at prefrontal level and transmitted into the striatal system. It is well possible that an increased MMN could also be observed in passive listening conditions (when sounds have to be ignored), because the MMN is comparably modulated regardless whether subjects attend or ignore sound. Such a result argues against the necessity of a goal state for the MMN (Schröger 2007).

In summary, our results show that a severe neurodegeneration as in HD is not necessarily related to a global decline of all cognitive abilities. Instead, improved functioning of specific cognitive processes can emerge together with a deterioration of other cognitive functions in late stages of the disease. It is the altered intrastriatal neuronal dynamics that probably produces this patchwork of parallel declines and improvements of cognition functions.

\section{References}

Ahveninen J, Jääskeläinen IP, Osipova D, Huttunen MO, Ilmoniemi RJ, Kaprio J, Lönnqvist J, Manninen M, Pakarinen S, Therman S, Näätänen R, Cannon TD (2006) Inherited auditory-cortical dysfunction in twin pairs discordant for schizophrenia. Biol Psychiatry 60:612-620.

Arning L, Kraus PH, Valentin S, Saft C, Andrich J, Epplen JT (2005) NR2A and NR2B receptor gene variations modify age at onset in Huntington's disease. Neurogenetics 6:25-28.

Aron AR, Watkins L, Sahakian BJ, Monsell S, Barker RA, Robbins TW (2003) Task-set switching deficits in early-stage Huntington's disease: implications for basal ganglia function. J Cogn Neurosi 15:629-642.

Beal MF, Ferrante RJ (2004) Experimental therapeutics in transgenic mouse models of Huntington's disease. Nat Rev Neurosci 5:373-384.

Berti S, Schröger E (2001) A comparison of auditory and visual distraction effects: behavioral and event-related indices. Brain Res Cogn Brain Res 10:265-273

Beste C, Saft C, Yordanova J, Andrich J, Gold R, Falkenstein M, Kolev V (2007) Functional compensation or pathology in cortico-subcortical in- teractions in preclinical Huntington's disease. Neuropsychologia 45:2922-2930.

Beste C, Saft C, Andrich J, Gold R, Falkenstein M (2008) Stimulus-response compatibility in Huntington's disease: a cognitive-neurophysiological analysis. J Neurophysiol 99:1213-1223.

Bolam JP, Hanley JJ, Booth PA, Bevan MD (2000) Synaptic organisation of the basal ganglia. J Anat 196:527-542.

Calabresi P, Centonze D, Gubellini P, Marfia GA, Pisani A, Sancesario G, Bernadi G (2000) Synaptic transmission in the striatum: from plasticity to neurodegeneration. Prog Neurobiol 61:231-265.

Cepeda C, Wu N, André VM, Cummings DM, Levine MS (2007) The cortico-striatal pathway in Huntington's disease. Prog Neurobiol 81:253-271.

Craufurd D, Snowden J (2002) Neuropsychological and neuropsychiatric aspects of Huntington's disease. In: Huntington's disease (Bates G, Harper P, Jones L, eds), pp 62-94. Oxford: Oxford UP.

Escera C, Corral MJ (2007) Role of mismatch negativity and novelty-P3 in involuntary auditory attention. J Psychophysiol 21:251-264.

Feigin A, Ghilardi MF, Huang C, Ma Y, Carbon M, Guttman M, Paulsen JS, Ghez CP, Eidelberg D (2006) Preclinical Huntington's disease: compensatory brain responses during learning. Ann Neurol 59:53-59.

Gajewski PD, Stoerig P, Falkenstein M (2008) ERP-correlates of response selection in a response conflict paradigm. Brain Res 1189:127-134.

Gratton G, Coles MG, Donchin E (1983) A new method for off-line removal of ocular artifact. Electroencephalogr Clin Neurophysiol 55:468-484.

Huntington Study Group (1996) Unified Huntington's disease rating scale: reliability and consistency. Mov Disord 11:136-142.

Ilvonen TM, Kujala T, Kiesiläinen A, Salonen O, Kozou H, Pekkonen E, Roine RO, Kaste M, Näätänen R (2003) Auditory discrimination after lefthemispheric stroke: a mismatch negativity follow-up study. Stroke 34:1746-1751

Javitt DC, Steinschneider M, Schroeder CE, Arezzo JC (1996) Role of cortical N-methyl-D-aspartate receptors in auditory sensory memory and mismatch negativity generation: Implications for schizophrenia. Proc Natl Acad Sci U S A 93:11962-11967.

Kalueff AV (2007) Neurobiology of memory and anxiety: from genes to behavior. Neural Plast 2007:78171.

Kreitschmann-Andermahr I, Rosburg T, Demme U, Gaser E, Nowak H, Sauer H (2001) Effect of ketamine on the neuromagnetic mismatch field in healthy humans. Brain Res Cogn Brain Res 12:109-116.

Kujala T, Tervaniemi M, Schröger E (2007) The mismatch negativity in cognitive and clinical neuroscience: theoretical and methodological considerations. Biol Psychol 74:1-19.

Landwehrmeyer GB, Dubois B, de Yébenes JG, Kremer B, Gaus W, Kraus PH, Przuntek H, Dib M, Doble A, Fischer W, Ludolph AC; European Huntington's Disease Initiative Study Group (2007) Riluzole in Huntington's disease: a 3-year, randomized controller study. Ann Neurol 62:262-272.

Mager R, Falkenstein M, Störmer R, Brand S, Müller-Spahn F, Bullinger AH (2005) Auditory distraction in young and middle-aged adults: a behavioural and event-related potential study. J Neural Transm 112:1165-1176.

Miller EK (2000) The prefrontal cortex and cognitive control. Nat Rev Neurosci 1:59-65.

Miller EK, Cohen JD (2001) An integrative theory of prefrontal cortex function. Annu Rev Neurosci 24:167-202.

Näätänen R, Winkler I (1999) The concept of auditory stimulus representation in neuroscience. Psychol Bull 125:826-859.

Näätänen R, Gaillard AW, Mäntysalo S (1978) Early selective-attention effect on evoked potential reinterpreted. Acta Psychol (Amst) 42:313-329.

Näätänen R, Paavilainen P, Rinne T, Alho K (2007) The mismatch negativity (MMN) in basic research of central auditory processing: a review. Clin Neurophysiol 118:2544-2590.

Paulsen JS, Zimbelman JL, Hinton SC, Langbehn DR, Leveroni CL, Benjamin ML, Reynolds NC, Rao SM (2004) fMRI biomarker of early neuronal dysfunction in presymptomatic Huntington's disease. AJNR Am J Neuroradiol 25:1715-1721.

Pekkonen E (2000) Mismatch negativity in aging and in Alzheimer's and Parkinson's disease. Audiol Neurootol 5:216-224.

Plenz D (2003) When inhibition goes incognito: feedback interaction between spiny projection neurons in striatal function. Trends Neurosci 26:436-443.

Ranen NG, Stine OC, Abbott MH, Sherr M, Codori AM, Franz ML, Chao NI, 
Chung AS, Pleasant N, Callahan C (1995) Anticipation and instability of IT-15 (CAg)n repeats in parent-offspring pairs with Huntington's disease. Am J Hum Genet 57:593-602.

Ravenscroft P, Brotchie J (2000) NMDA receptors in the basal ganglia. J Anat 196:577-585.

Schröger E (2007) Mismatch negativity. A microphone into auditory memory. J Psychophysiol 21:138-147.

Schröger E, Wolff C (1998) Attentional orienting and reorienting is indicated by human event-related brain potentials. Neuroreport 26:3355-3358.

Schröger E, Giard MH, Wolff C (2000) Auditory distraction: eventrelated potential and behavioral indices. Clin Neurophysiol 111:1450-1460.

Schröger E, Tervaniemi M, Huotilainen M (2004) Bottom-up and topdown flows of information within auditory memory: electrophysiological evidence. In: Psychophysics beyond sensation: laws and invariants of human cognition. Scientific psychology series (Kaernbach C, Schröger E, Müller HJ, eds), pp 389-407. Mahwah, NJ: Lawrence Earlbaum Associates.
Schröger E, Bendixen A, Trujillo-Barreto NJ, Roeber U (2007) Processing of abstract rule violations in audition. PLoS One 2:e1131.

Tepper JM, Koós T, Wilson CJ (2004) GABAergic microcircuits in the neostriatum. Trends Neurosci 27:662-669.

Tunstall MJ, Oorschot DE, Kean A, Wickens JR (2002) Inhibitory interactions between spiny projection neurons in the rat striatum. J Neurophysiol 88:1263-1269.

Umbricht D, Koller R, Vollenweider FX, Schmid L (2002) Mismatch negativity predicts psychotic experiences induced by NMDA receptor antagonist in healthy volunteers. Biol Psychiatry 51:400-406.

Villmann C, Becker CM (2007) On the hypes and falls in neuroprotection: targeting the NMDA receptor. Neuroscientist 13:594-615.

Voermans NC, Petersson KM, Daudey L, Weber B, Spaendonck KP, Kremer HPH, Fernández G (2004) Interaction between the human hippocampus and the caudate nucleus during route recognition. Neuron 43:427-435.

Yohrling GJ, Cha JHJ (2002) Neurochemistry of Huntington's disease. In: Huntington's disease (Bates G, Harper P, Jones L, eds), pp 276-309. Oxford: Oxford UP. 